\title{
Mixed Tumor of the Skin (Chondroid Syringoma)
}

National Cancer Institute

\section{Source}

National Cancer Institute. Mixed Tumor of the Skin (Chondroid Syringoma). NCI

Thesaurus. Code C4474.

A rare, benign, slow-growing and painless neoplasm of sweat glands. It usually arises in the head and neck. It is characterized by the presence of a mesenchymal chondroid stroma, fibrosis, and epithelial structures. 